\title{
Can International Local Government Partnerships Make a Difference? Lessons from the Australia - Papua New Guinea Good Practice Scheme
}

\author{
Donovan Storey ${ }^{1}$ \\ University of Queensland
}

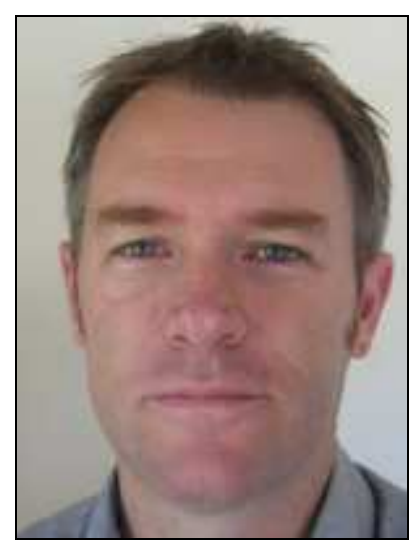

\begin{abstract}
This article explores the contribution that local government to local government partnerships can make in bringing about more effective and sustained decentralisation through developing the capacity of local governments to deliver improved services to the communities they serve. After almost 15 years of decentralization many of Papua New Guinea's local governments struggle to maintain essential functions. Building on existing relationships, the Commonwealth Local Government Good Practice Scheme seeks to utilize the resources and knowledge of Australian local councils in partnership with those in Papua New Guinea to build capacity and improve the management and delivery of services to communities. This article examines the program to date, outlining both the successes and
\end{abstract}

\footnotetext{
${ }^{1}$ This article has benefited greatly from the comments and reflections of CLGF Pacific Project staff, namely Terry Parker, Ted Lulu, and Karibaiti Taoaba, as well as two independent referees. The author is solely responsible for the conclusions drawn here and they do not necessarily represent the views of CLGF staff.
} 
failures, but also the potential role such partnerships can play in the deepening of democratic governance at the local level.

Keywords: Twinning, capacity building, service delivery, Australia, Papua New Guinea

\section{Introduction}

Decentralisation and local government performance continues to be at the forefront of governance transformations in many developing countries in the Commonwealth and beyond. As is evident in the considerable literature which exists on decentralisation, there are a number of benefits but also difficulties in devolving genuine responsibility, authority and accountability to local governments. Far from being the 'magic bullet' in the good governance agenda, which gained much traction among donors throughout the 1990s, decentralisation and the greater emphasis given to local government has resulted in a number of quite diverse outcomes and experiences (see Blair 2000). While the majority of those involved in service delivery and the development of effective institutions remain committed to devolution, there is greater awareness today of the pros and cons of a multitude of decentralisation models and strategies.

For some writers, the difficulties faced by incipient local authorities reflect the limits of approaches to governance that have been framed too greatly by aid donors and international 'best practices' (Kunzmann 2005). Existing forms of local governance, including traditional models, may provide resistance to 'outside' or 'imposed' models, including those devised and implemented by national governments (May 1999, pp. 144-145). This suggests that there is still a great deal to be learned from both the experiences of decentralisation but also the dynamics that may support or impede change (see Blair 2000; IIED 2004; Batterbury and Fernando 2006; Prinsen and Tetica 2008).

This article explores the contribution that twinning, or local government to local government partnerships, ${ }^{2}$ can make in bringing about more effective and sustained decentralisation through developing the capacity of local governments to undertake core tasks. Such

\footnotetext{
${ }^{2}$ Such agreements are also referred to as International Municipal Linking (by Spence and Ninnes 2007); International Municipal Cooperation (Hewitt 1999); twinning (Zelinsky 1991); sister city relationships (Cremer et al. 2001); and institutional collaboration (Askvik 1999).
} 
relationships go beyond 'sister-city' linkages (though they may build upon them) by endeavoring to provide specific support to improved governance, service delivery, planning and sustainable urban development, amongst other goals. Ideally, such relationships aim to develop a sense of partnership, in which both authorities learn from each other's experiences and strengths over a period of time. Time and trust is important in relationships (Swain and Tait 2007), in that the ultimate outcome is not the time-bound transfer of resources, aid or expertise from 'developed' to 'developing' countries, but rather the establishment of networks which can respond to needs, opportunities and possibilities as they arise. ${ }^{3}$

The growth of 'twinning' dates back to post-war strategies to develop better links, forms of communication and understanding between countries through city governments. Indeed, a number of early partnerships were between cities in the United Kingdom and Germany with shared experiences of post-war reconstruction (e.g. Coventry and Dresden). In more recent years the geographical focus has shifted to include linkages between local governments in developed countries and developing country authorities (Cooper 1984), but relationships have also broadened to be inclusive of civil society, educational institutions, health providers and so on (Green, Game and Delay 2005). The scope of international local government partnerships, including the Commonwealth Local Government Good Practice Scheme (GPS), is then quite varied, and can range from increasing financial capacity and systems (creating 'bankable cities' for trade and investment opportunities), to initiating HIV/AIDS prevention programmes (CLGF 2009). The breadth of such relationships makes for a variety of examples and outcomes, which only loosely follow a 'model' of exchange and capacity building.

Twinning has thus become a framework for a range of bi-lateral partnerships, but also broader networks and clusters. Developed- developing country programmes, for example, are increasingly funded and facilitated by international donors (such as the UK Department

\footnotetext{
${ }^{3}$ Leeds City Council provides somewhat of a benchmark in embedding a number of objectives into a broader international relations focus for the council and city in general. This includes using partnerships to develop a sense of global citizenship for the people of Leeds; using linkages to increase business contacts and opportunities; increasing cultural enrichment opportunities for its increasingly multicultural population through international festivals, exchanges and other programmes; and developing expertise and contacts to a level which allow the city to bid for EU and other externally funded projects (Leeds City Council 2008). Far from being a part time or external activity, the development of international partnerships with cities such as Durban, Colombo, Dortmund and Hangzhou is seen as integral to increasing the global competitiveness and integration of the city as a whole.
} 
for International Development [DFID], AusAID, the European Union etc), as part of their stratagem of promoting decentralisation and democratic institutions, improved service delivery and attaining Millennium Development Goals (MDG) targets. International partnerships at the level of the city (for instance the Canadian Municipal Partnerships Program and US City Links), mayoralties (e.g. 'City Mayors' network) and civil society (e.g. Shack/Slum Dwellers International) are all reflections of the belief that networks can strengthen capacity and produce better outcomes for cities and their citizens. Indeed, promoting networks or clusters which include multiple local governments has become a favoured approach for bilateral and multilateral donors as well as development agencies. Given the increasing significance of urban centres to national prosperity and development (World Bank 2008), van der Pluijm (2007) has suggested that city-to-city development strategies may be a favoured form of development aid in the future. Partnerships have also created opportunities for networks to emerge within countries, where, for example, several councils may collaborate with clusters of counterparts overseas. It has been argued that this has moved local governments away from a competition framework toward collaboration, in which they may share experiences, build expertise and develop trust (Sykes 2002). The GPS, discussed below, is therefore one example amongst many.

Despite the existence of (albeit varied) local government partnerships over a number of decades, Spence and Ninnes (2007) have noted the limited research and sharing of lessons from (especially) council-to-council links. What literature does exist has generally been supportive of such strategies, though noting several problem areas. Writing on the TorontoSao Paulo Cooperation Agreement, Hewitt (1999) found considerable improvement in emergency response services, urban planning and service delivery in Sao Paulo, where previous donor 'loan and grant' approaches had shown less obvious benefits over time. In examining a number of 'Friendship Agreements' between local councils in Australia (essentially Victoria) and Timor Leste, Spence and Ninnes (2007) also concluded that initiatives, when underpinned by a committed and long term approach based on trust building and partnership, had led to positive outcomes in a range of areas, such as waste management; the creation of coffee markets for Timorese farmers; improved water provision; medical supplies and so on. This variety of outcomes reflects both the strengths and perhaps weaknesses of partnership frameworks in that they are responsive to need and opportunities as they arise, but they may also be seen as ephemeral and lacking a coherent 
approach and set of sustained outcomes which result in stronger local governments over time.

A number of problems have subsequently been recognized. These have identified challenges of maintaining channels of communication; continuing political support (including resources) over time; avoiding the temptation to simply 'deliver' outputs and outcomes, especially (but not only) from developed to developing country councils; managing expectations of both 'northern' and 'southern' councils and staff; the impact of political systemic change (especially the dissolution/merging of councils or shifts in levels of authority between local, provincial and national governments); the sustaining of change over time, especially vis-à-vis expectations; and difficulties in monitoring and evaluation, which may also threaten programs in budgetary priorities (Hewitt 1999, pp.40-41; Ninnes and Spence 2007, pp. 337-339). Many inter-institutional partnerships also depend upon the energy and commitment of individuals, and can fade as personnel change over time if relationships are not effectively institutionalized.

\section{The Commonwealth Good Practice Scheme in Context}

The Commonwealth Local Government Good Practice Scheme (GPS) dates to 1998 and is "designed to support the implementation of focussed projects, based on the exchange of good practice and skills between practitioners working in the field of local government ... to help councils improve the efficiency of service delivery and local democracy" (CLGF Pacific 2008). GPS initiatives are not designed as stand-alone projects, but are technical inputs to the core business of councils. The Scheme has recently entered its third stage (2008-2011) with a focus on 'improving governance for service delivery', with expanded partnerships planned for Jamaica, South Africa, Sierra Leone, Ghana, Pakistan and India (CLGF 2007). This exchange is facilitated using council partnerships "to promote effective, responsive and accountable delivery of local authority services, particularly to poor and disadvantaged communities" (Parker and Praeger 2008, p. 8). As such the goals of the Scheme are ideally reflexive, and encompass promoting effective, responsive and accountable delivery of local government services; improving implementation capacity of local authorities; identifying examples of good practice for implementation elsewhere; and improving planning and management performance. 
The focus on service delivery is important and deliberate, as this is seen by project staff as an outcome which is measurable, builds the capacity and legitimacy of local government, and meets a number of donor and national policy objectives, not least several of the Millennium Development Goals. The association between service delivery and decentralisation is entwined in recent discourses supporting a greater role of local government in development (Batterbury and Fernando 2006, p. 1851). In the case of infrastructure provision, a recent comparative study of nine cities in the developing world demonstrated that inadequacies in infrastructure and service provision "relate as much to the inadequacies in government structures as they do to a lack of ability to pay" (Nunan and Satterthwaite 2001, p. 409). AusAID's Australia-Papua New Guinea Development Cooperation Strategy 2006-2010 makes explicit links between improved service delivery, stability, good governance and decentralisation (AusAID 2007, p. 32). In addition, recent GPS documents link decentralisation, service delivery and poverty reduction, further associating local government to contemporary development discourses and ambitions (Storey et al. 2005)

Nevertheless, despite these strong claims, the link between capacity building of local government, service delivery and better governance remains contested in the Pacific and beyond (Duncan 2005). Haley (2008, p. 7) has noted that service delivery per se has only a weak correlation with participatory and accountable governance - 'despotic' and corrupt leadership may bring about improved services irrespective of citizen input or the existence of competent democratic institutions, if they have adequate resource streams. Likewise, citizens may see democracy as an impediment to service delivery if it results in a lack of responsiveness, efficiency and outcomes. Consequently, the provision of infrastructure and services can play an important role in strengthening participatory decision making (an example being the Orangi Pilot Project in Pakistan; Hasan 2006), or can have only a minor impact. The relationship between services, poverty eradication and governance is thus complex and likely to be strongly context specific. A lack of capacity and resources within government; the lack of institutional means to coordinate investment and projects of multiple agencies and levels of government; and a lack of mechanisms and transparent systems of accountability through which people can monitor the decisions and actions of private and public agencies, are all cited as contributing factors linking poor governance and inadequate service provision (World Bank 2004). 
Consequently, the GPS seeks to go beyond simply transferring resources from one council to another in order to 'supply' services. Progress instead is measured in terms of the ability of councils to develop into competent, inclusive and dynamic organisations which maintain positive ongoing relationships with civil society (CLGF Pacific 2008). Nevertheless, a tension remains between service outcomes, as evidence of progress, and the process of establishing demand-side governance, which may involve a much longer time frame and be less measurable. For citizens who are yet to receive adequate water, sanitation or other services from councils, and for councils and donors that must justify such a commitment in financial and human resource terms, the temptation is to 'deliver' services. But rarely does such an approach build the integrity of local government or sustain democratisation at the local level. As Blair (2000) has noted, citizen participation is essential for the sustenance of democratic, responsive and accountable institutions over time.

\section{The Good Practice Scheme in the Pacific: Linking Australia and Papua New Guinea}

Following on from the broader Commonwealth Local Government Good Practice Scheme, in 2000 the CLGF Pacific Project partnered with AusAID and the Government of Papua New Guinea (GoPNG), through the Department of Provincial and Local Government Affairs, to extend opportunities for councils in PNG to participate in the programme. This built upon existing relations between Australian and PNG local councils as well as other new partnerships and networks being initiated to support local government capacity building in the Pacific. Papua New Guinea was selected as the target country as several partnerships already existed with local governments in Australia, and such a focus complemented both AusAID's Sub-National Strategy in PNG as well as GoPNG efforts to more successfully decentralize central government functions (AusAID 2007; GoPNG 2006). In 2008 the GPS entered a second phase (2009-2011) with the goal to "enhance urban livelihoods through improved governance and service delivery at the local government level", thus further linking decentralisation and local government to the outcomes of poverty reduction through more responsive and efficient provision of services (CLGF 2008:5).

The Pacific GPS promotes council-to-council partnerships and funds practical capacity building and technical support for projects which are designed to draw on the knowledge, skills and expertise of local councils in both Australia and PNG. These activities are 
reflective of the skills and expertise of participating Australian councils, as well as the target needs and core business of local government partners in Papua New Guinea. Promoting good governance and local democracy is sought through the exchange of skills and ideas, capacity building, and fostering collaborative approaches to problem solving while working with resource constraints. ${ }^{4}$ While service delivery is seen as a paramount and important objective and outcome of relationships, observable or felt benefits for communities are also important (CLGF 2008). However, as is evident in the discussion which follows, the impact of the GPS in bringing about these goals across the partnerships has to date been uneven.

Both Papua New Guinea and Australia have undergone significant decentralisation and changes in the relationship between national, provincial/State and local government over recent years. Though local government was recognized in the Papua New Guinea Constitution at independence in 1975, it was the Organic Law on Provincial Governments and Local-Level Governments (1995) and the Local-Level Governments Administration Act (1997) that gave the principal legislative direction and mandate for the country's 299 local authorities (Hassell and Tipu 2008; see Filer 2004 for a concise summary of these two Acts). The 1997 Act entrusts local government with responsibilities to develop roads and parks, refuse collection and disposal, health and environmental protection, economic promotion and tourism, though funding remains primarily external and channeled downward, through central and provincial grants and other financial support.

Australia too has a three-tiered governance structure in which responsibility and accountability is spread across federal (national), state and local government. Perhaps an important point of difference lies in the fact that local government is increasingly understood as one of the three spheres of government, rather than the bottom tier (as is often lamented by local government officials in PNG), although it lacks recognition in the federal constitution and exists and operates largely as the states see fit. There remain tensions in the distribution and discharge of functions across levels of government, as well as the capacity to meet needs. Remote and indigenous local authorities arguably face similar problems to under-resourced and over-stretched councils in the Pacific, especially in meeting the needs of poor, isolated and inadequately serviced communities with a limited revenue base. As

\footnotetext{
${ }^{4}$ AusAID financial support for the 2009-2011 Phase is AUD3.4 million, while 'in-kind' commitments from participating councils has been estimated at AUD1.2million over the three years.
} 
elsewhere, Australian councils have undergone changing structures and functions over time (Caulfield 2003). Most recently, in 2008 a large number of Queensland councils went through significant amalgamations which resulted in shifts in their socio-economic character, as well as revenue streams (State of Queensland 2007). All these factors impact on the capacity and readiness of Australian councils to participate in international partnerships.

Reflecting the current majority rural population (82\%) the overwhelming number of PNG local authorities are rural councils (273, or 91\%). Nevertheless, it is arguably in PNG's rapidly growing urban areas where the pressures facing local authorities are most acute (Connell 1997). Very few of the country's 26 urban councils have the financial and human resources to adequately perform their roles and service functions. Many are caught between declining opportunities to raise revenue from decidedly poor urban populations, and perennial annual tensions with provincial and national government in securing grants and their share of redistributive funds (the Organic Law provides for revenue sharing across local governments but rarely does this system function effectively or transparently). As a result, municipal councils are often left with little more than subsistence funding, and a great proportion of local government budgets are spent on paying approximately 6,500 councillors and council staff.

It is important to note that local government, and the decentralisation experience in general, has a number of critics. After nearly two decades of decentralisation questions remain regarding the means and ends of supporting local bodies in addressing the many needs of communities. Schoeffel (2003) provides a useful summary of the dangers in seeking answers to governance problems in the Pacific solely through a focus on local government. In particular, arguments in favor of decentralisation as an antidote to the failures of national and provincial governance overlook interrelationships between levels of government. As such, decentralisation does not transcend or compensate for broader political failure. Local government may in fact replicate previous problems of poor governance, a lack of resources, corruption or ambivalence to community needs (Schoeffel 2003, p. 4). Local government has also been plagued by problems of capacity in planning, but also in implementation. Corruption has been an additional blow to credibility, illustrated by the dissolution of the National Capital District Commission in 2000. Moreover, local governments have struggled to develop relationships with communities through participatory planning and by bridging 
gaps between bureaucratic and traditional systems (see Storey 2005), as well as to establish effective links with other tiers of government. Conflict and competition with provincial authorities is prevalent in a number of provinces (Filer 2004).

\section{Case Studies}

This article examines the experiences of four local council-to-council partnerships under the GPS programme. In so doing it draws upon a number of sources. These include key design documents of the GPS in both the Pacific and globally; reviews of the Australia-Papua New Guinea partnerships conducted over the past five years; critical reflections of staff involved in the programme; as well as discussion which took place during a dissemination workshop involving partners in the GPS from both Australia and Papua New Guinea, held at Noosaville, Queensland on 29-30 May, 2008. The purpose of the workshop was to draw out the key lessons from the respective projects, particularly focusing on any approaches and policy recommendations which would be relevant and could be shared more widely in Papua New Guinea and Australia. Key participants included local government officials from Australia and PNG; representatives from the PNG Urban Local Level Government Association (PNGULLGA), Australian Local Government Association (ALGA), and the Queensland State Department of Local Government; and officers of the Commonwealth Local Government Forum Pacific Project. ${ }^{5}$

The four partnerships are first described and critically assessed with regards to their progress and against the objectives of the CLGGPS, in order to draw out lessons on the role of international partnerships in developing and strengthening local government. In particular the case studies are assessed against the core objectives of more effective service delivery; improved planning and management performance; and the capacity of local councils. Overlaying this is the expectation of improved governance and increased benefits for poor and disadvantaged groups. As will be evident this is not a straightforward task. In order to ensure flexibility and respond to the core goals of participating councils, each partnership defines its own objectives and pathways. While this allows for responsive and organic

\footnotetext{
${ }^{5}$ The author was responsible, with CLGF staff, for writing an evaluation of findings from the Noosaville workshop. This article builds upon but also departs from that review, in offering a more critical reflection of the GPS. In so doing the comments herein do not necessarily reflect the views of CLGF staff on the progress of the GPS to date.
} 
approaches to problems identified by both Australian and Papua New Guinean councils, it does make comparative and conclusive inferences based on a common set of indicators difficult.

The Good Practice Scheme has been supporting four council-to-council projects (and one local government association to association project) in Papua New Guinea, each of which has been addressing issues identified as priorities by the project partners. These issues have included waste management, town planning, information technology, regulatory services and corporate planning. This article will focus on the current partnerships linking Townsville and the National Capital District Commission (Port Moresby); Orange and Mount Hagen; Cairns and Lae; and Noosa (now Sunshine Coast) and Alotau (Milne Bay).

\section{Townsville Regional Council ${ }^{6}$ and National Capital District Commission}

Before joining the GPS in 2002 the National Capital District Commission (NCDC) and Townsville had an established sister city relationship (since 1983). Under the GPS both partners have endeavoured to improve the planning capability of NCDC by strengthening the Regulatory Services division. To date, this division has struggled to formulate plans and carry out its functions, including developing strategic evidenced-based policies which can respond to the multifarious needs of the estimated 500,000 population of Port Moresby. As such the NCDC has become a notable bystander in the growing informalization of the city's development.

The Townsville-NCDC partnership (known as 'Hetura' or Friendship) has taken place in two phases. Phase One of Hetura encompassed the period 2002-2006, over which the focus was on building the capacity of the NCDC's Regulatory Services to improve its planning capability and increase levels of compliance (TCC/NCDC 2007). This involved technical exchanges and training where Townsville City Council provided expert advice on key problems; in particular how to develop sound business practices through strengthening organizational (departmental) structures; increasing human resource capacity and enhancing performance; developing better policy formulation, operational procedures and information technology systems; and strengthening financial management and corporate information systems (NCDC/TCC 2008).

\footnotetext{
${ }^{6}$ Formerly Townsville City Council until its amalgamation with an adjoining council in 2008.
} 
Despite periods of political and financial turmoil in the NCDC, Phase One of Hetura was largely seen as successful in terms of achieving greater information technology (IT) capacity, development control of food outlets, and approval of strategic plans such as the National Capital District (NCD) Urban Development Plan, Port Moresby Town Local Development Plan, and the NCD Settlements Strategy 2007-2011. These have all provided frameworks for the future planned growth of the city and set priorities for infrastructure development, though notable problems with implementation and key stakeholder buy-in remain. There were modest improvements in operational procedures in strategic planning, compliance processes, customer services, records management and debt recovery. As part of this a website was launched in 2005 (www.ncdc.gov.pg) which makes planning documents, application procedures, forms and service charges available online, though very few of the city's population have access to the internet. Improvements in the IT capacity of the NCDC were made at a cost of approximately K1 million (A $\$ 470,000)$ (TCC/NCDC 2008).

Hetura II seeks to create a 'one stop shop' of regulatory services, supported by 'state of the art' technology to improve services, manage customer and planning applications and improve enforcement (including cost recovery). This has resulted in improving the rating and revenue performance of the NCDC (CLGF 2008:10). In addition, efforts have also focused on developing more effective strategic plans for the city's growing number of informal settlements; and creating better integration of the NCDC with key government agencies. The lack of such relationships has frustrated a number of potential initiatives in the past. Hetura II has thus focused on creating a more dynamic governance structure which involves a project steering committee at management level to set the strategic direction of the partnership, as well as more regular visits and exchanges of staff (including technical officers). 'Learning clusters' in specific areas of capacity need have emerged between NCDC and Townsville staff.

Though portrayed as successful a number of constraints have also been apparent in Hetura, which reflect the difficulties faced in transforming institutional governance and systems. Restructuring of human resources has proved a slow and difficult process. Though a number of new policies and regulations have been developed, problems with enforcement remain. Penalties for violations of planning codes, environmental degradation and so on remain insignificant and/or unenforced. The Settlements Plan 2007-2011 has made limited headway, 
as it has weak links with many of the communities affected, as well as to other key government departments, such as the Ministry of Lands and the Office of Urbanization (which has its own set of urban policies). The cost of implementation, in effectively dealing with the housing conditions and service needs of an estimated $60 \%$ of the NCDC's population who live in informal settlements, is estimated at K36 (A $\$ 17)$ million. This is well beyond the financial capabilities of the NCDC and key stakeholders. Engagement with the broader population, especially the poor, remains narrow. While enhanced financial services and technology have increased internal capacity and the potential for greater revenue streams, the broader governance goals of creating responsive, efficient and 'pro-poor' institutions can be considered, to date, as largely unmet. One of the lessons from Hetura is the challenge which lies in the transfer of better systems and more comprehensive planning to the level of program delivery and management.

\section{Orange and Mount Hagen}

The relationship between Orange City Council and the municipality of Mt Hagen is notable for its longevity, dating back some twenty years. Mt Hagen is a rapidly growing Highlands city with an estimated population of approximately 80,000. It faces considerable challenges in managing the growth of informal settlements and the complex social relationships which characterize its geo-cultural setting. A number of initiatives addressing land use, capacity building and town planning have been launched in the past but with limited success. Overall, Mt Hagen council remains a relatively fragile institution facing considerable pressures and demands. This was highlighted in mid-2008 with the near collapse of the council due to a financial crisis, in part ensuing from a standoff with provincial government over a lack of funding and leading to a cessation of municipal services and functions (Radio Australia 2008).

Since joining the GPS programme the partnership between Orange and Mt Hagen has encompassed developing land use maps and strategic plans, creating more pedestrian friendly spaces (walkways and crossing points), and conducting settlement surveys. Initiatives have also included dealing with solid waste management issues, with staff from Mt Hagen attending an international waste conference in Australia in 2007. Refurbishment of the market place has also been completed. These accomplishments reflect a strategy of creating 'demonstration' projects which impact positively on people's lives and are 
associated with local government as a service provider. Of some significance, senior provincial politicians have been invited to opening celebrations of new projects, thus utilizing opportunities through projects to build broader support for the Mt Hagen council as well as the GPS in general.

There has been a focus on planning and on the process of defining and implementing planning priorities. In 1999 Mt Hagen approached Orange for assistance in developing an Urban Development Plan (UDP, 2007-2017). In 2007 this was completed and approved by the National Lands and Physical Planning Board. From the Plan, a number of strategic directions in land use, waste management, livelihood support etc were identified, which provide entry points for future support and direction. But achievement was also measured in terms of the capacity building of staff in developing the plan, as well as the consultative processes with communities which established key needs of the city and its residents.

The partnership has also looked at ways of supporting economic development opportunities for women through the export of crafts, string bags and other handicrafts to Orange. Though in its early stages, this represents an attempt to broaden cooperation between Orange and Mt Hagen toward creating opportunities for enhanced livelihoods, as is evident in the case of Australian partnerships with Timor Leste (Spence and Ninnes 2007).

The relationship between Orange and Mt Hagen is valuable in terms of understanding the dynamics of long term partnerships but also in the transfer of improved institutional systems to services, infrastructure and participatory approaches to planning. Coupled with the development of an urban plan for Mt Hagen, project partners have strategically delivered and heralded small scale projects which positively impact on lives, such as a cleaner central city, new footpaths, improved traffic islands and safer walkways. Nevertheless, given the substantial growth of Mt Hagen, modest gains in infrastructure and services can easily become overwhelmed by demands and needs. Sustaining progress in council systems and capabilities as well as providing essential services will likely be an ongoing challenge requiring significant innovation and investment. 


\section{Cairns Water and Lae- the Asitawa Waste Management Strategy}

Cairns and Lae have been working together since 2002 on an integrated waste management strategy for the city of Lae for a number of years. Lae, as the second largest city in Papua New Guinea, functions as an industrial hub and the most important metropolitan centre of the Momase and Highlands Region. Waste management in particular has been identified as a great challenge for the local authority to manage. In response, Cairns has provided technical expertise and advice in the development of an appropriate waste management strategy. As a way to raise a sense of community awareness and support, Lae council named the project in their local dialect 'Asitiwa' Waste Strategy, meaning 'caring for our waste'.

Following donor (AusAID) approval of the programme, Cairns commenced a scoping exercise to assess the waste situation in Lae and had preliminary discussions with the Lae council on how a waste strategy could be developed. An initial agreement settled on activities over a period of six months. It was also agreed that contributions were to be made in-kind by partners. This included staff time and other resources needed to support the project and to equip project staff with necessary equipment.

The scoping for the project included consultations with council members, managers, stakeholders, business and academic institutions. These consultations resulted in the preparation of a Draft Waste Management Development Strategy framework and the establishment of a Project Steering Committee that would be responsible for planning and execution of project activities as well as overall implementation of the strategy.

The development of the strategy was planned to cover the period 2004 to 2014 and provide integrated solutions for waste management. The strategy focuses primarily on responding to emerging environmental problems through institutional capacity building, in particular by developing and implementing a waste minimisation programme and Master Plan for Waste Development; by educating the public on solid waste problems; by improving public health; by encouraging the recycling and safe use of organic and inorganic waste; and by establishing a landfill which could deal with demands over a twenty year period (LULLG 2003). 
Despite this planning process the waste management strategy has still to be formally launched. In the words of a Lae local government official: "a six month project has taken us seven years!" In large part this is because the relationship between Cairns and Lae did not progress past the planning stage. The focus was on 'the Plan', but there was a lack of resources and ability to implement those good intentions. Budgetary support for the project did not eventuate, beyond that for some travel and workshops, and this led to confusion over responsibilities on how the project could proceed. Without adequate and secure funding for implementation, available land for new landfill, or adequate infrastructure support, the capacity of Lae to implement a sustainable programme made even launching the project problematic. In addition to the lack of physical and other resources, staff in Lae lacked the technical capacity to take ownership of the original objectives.

In essence 'the Plan' became the end of the partnership, rather than the means of broader change (CLGF 2008:12). Partly this was due to the relationship being one between the Lae council and Cairns Water, a business arm of Cairns City Council. While this offered a high level of technical expertise, there was a lack of governance strengthening to create capacity for implementation. The project received little input or commitment from other key government agencies and landowners. It also suffered from staff changes at Cairns City Council. This lack of institutionalization of the project left it without champions and as a result it has failed to take root.

\section{Sunshine Coast Regional Council and Alotau}

The former Noosa council and Alotau commenced their partnership in 2007, shortly before Noosa was amalgamated with adjoining councils to form the Sunshine Coast Regional Council. Following scoping visits by Noosa officials to Alotau in 2006, the two councils agreed to work together to improve solid waste management services in Alotau, and in particular to develop a waste management plan. Waste management was chosen as Noosa council had a number of staff with necessary expertise, knowledge and interest, and this also matched Alotau's needs and strategic priorities. Although Alotau's population is only around 10,000 , the town suffers from significant waste mismanagement which has the potential to negatively impact on the area's strong tourism potential (Noosa Council 2008). 
The partnership has sought to increase financial resources for waste management and the council's other activities through enhanced IT skills and systems, especially in order to aid in billing and cost recovery. Decreasing the amount of litter and improving the dump facility were also important objectives (SCRC 2008). Results have been evident in the development of a workable billing system after installation; the creation of limited short term employment opportunities for youth; increased responsibility and ownership over installed litter bin stands; and the creation of a local litter control committee that supports and promotes the GPS initiative through providing community and stakeholder feedback. The creation of such a committee was seen as a way to publicize activities as well as to develop a sense of community responsibility in supporting projects. There have been efforts in community education on solid waste management and its relationship to health and the tourism potential of Milne Bay, as well as initiatives to engage the community more in waste separation, collection and service functions. Radio programmes have been used to increase knowledge of projects and of environmental issues in general (SCRC/ALLG 2008b).

The financial limitations of the Alotau council remain an impediment to improving service delivery. Alotau council has a very limited revenue stream and relies heavily on grants from provincial and national government to maintain its operations. Nevertheless, despite these constraints a number of key objectives have been met, particularly in terms of promoting community wide involvement and encouraging partnership with local stakeholders through the use of media, consultative local committees and offering livelihood opportunities for youth in waste management campaigns. Of the GPS case studies examined here, the Sunshine Coast-Alotau partnership is perhaps most explicit in establishing a relationship between enhanced technical capacity, public engagement/ownership and improved infrastructure and services. ${ }^{7}$

However, limited capital and human resources has made moving beyond modest projects potentially problematic. Also, concern that new technology may displace workers has meant that solutions to waste management problems have had to maintain jobs as a primary objective. To ensure that processes and infrastructure can be sustained locally and not result in the loss of employment, projects necessarily have to be small in scale (SCRC/AALG 2008a). However, weighed against this is the need to use increased capacity to implement

\footnotetext{
${ }^{7}$ No doubt the small size and relative safety of Alotau are important factors here.
} 
successful projects at a scale sufficient to provide tangible evidence of achievement. The Alotau experience, when evaluated in comparison to the larger Papua New Guinea councils, illustrates that strategies of capacity building and the exercise of such capacity should be sensitive to and reflect the norms and expectations of communities, as much as any 'model' of local government 'good practice'.

\section{Conclusions: Themes and lessons from the partnerships}

A number of important themes and lessons emerge from the GPS in Papua New Guinea in understanding relationships between local government capacity, service delivery, democratization and poverty reduction. The first is that time, and the building of trust and relationships, is a critical factor in successful outcomes (see Swain and Tait 2007 on the issue of trust in effective planning). Sustaining relationships has required participation and involvement from elected leaders as well as technical staff. Problems have emerged when a succession strategy was not in place to deal with changes in staff. Taking time in order to scope projects which are realistic, affordable, and can be sustained locally has proved to be important. In the case of Orange and Mt Hagen it took more than a decade to build trust and partnerships in order to move forward. Though this represents a longer process than most, it does indicate the importance of time as a factor in creating successful partnerships which result in tangible outcomes.

Successful interventions also needed to go beyond single-issue projects and extend into much longer and broader strategies that drew together a range of stakeholders, especially civil society and other tiers of government. Community engagement in the planning and design of projects is critical to success, but has been a challenge facing all partnerships and programmes at one time or another, and has often been too limited. Greater community engagement is needed at all levels of government in Papua New Guinea, however, and is not limited to the GPS. Devas (2001) has argued that there are limits in the benefits of decentralisation without a corresponding enhancement of the voice of recipients. Advancing the rights and power of citizens is integral to improved governance (IIED 2004). In contrast 'supply side' training can prove ephemeral and weakly linked to better development outcomes (Klitgaard 1997). Much can be learned from both the Orange/Mt Hagen and Sunshine Coast/Alotau partnerships in terms of lessons from community engagement, and in transferring gains in technical capacity into observable improvements in planning and 
implementation. While developing the capacity of local institutions to manage themselves and their financial and other systems is important, it cannot be an end in itself. Indeed, it is arguable that capacity and legitimacy results as much from 'doing' development through collaboration, as from improvements in design and planning.

Financial and other forms of capacity must be realistically assessed. As a form of development assistance, the GPS has been described as very cost effective (in part through the use of in-kind resources and time) (Mellor 2004:5). Overstretching in terms of commitment and expectations is an ever-present danger, but there has to be real operational activity, and councils must be seen to be doing something tangible for the community. Where success was evident it typically involved incremental gain, learning and adapting, rather than starting from a position of expecting immediate results. In essence, this involves developing local governments into 'learning organisations' rather than 'training recipients' (Jones and Blunt 1999). In particular, Australian councils participating in the GPS have learned that there are inherent limits to rapid change and acceptance of new ideas, as well as a need to address concerns about the potential impact of change - especially if this involved legal matters, whole-of-government buy-in, or sensitive issues such as land tenure. Projects which depended on the coordination of a number of stakeholders were typically problematic. Planning in the first instance for what the partners could control, while progressively building relationships with other key stakeholders, appeared to be the basis of success.

Effective projects appeared to involve a high degree of innovation, collaboration, and trial and error. There are clear limits in the expertise of Australian councils working within the Papua New Guinea socio-political and development milieu. While there are exhortations to develop ideas and partnerships, over time and sensitive to context, the political and cultural environment in which planning, decision-making and implementation must take place is perhaps less well understood (Sanyal 2005). Building sustained partnerships with communities remains a challenge as much as an opportunity, partly due to the vagueness of who these target populations are, the nature of their needs, and how local government can play a role. This is a broader challenge facing governance at all levels in Papua New Guinea: what are the needs of communities and how can these best be met? While the GPS, as a technical programme, can assist in several areas of local government responsibility, it can only play a small part in addressing these broader challenges (May 1999; Schoeffel 2003). 
Overall, therefore, the Good Practice Scheme partnering local and regional councils in Australia and Papua New Guinea offers mixed evidence but valuable lessons on whether such partnerships can make a significant difference to the capacity and performance of local government, especially with regard to service delivery and poverty reduction. That the evidence is mixed is not altogether surprising, and does not represent a failure per se. Local government remains generally unproven in the Pacific Islands context, and this provides opportunities of sorts. The GPS experience offers support for the benefits of approaches which result from smaller scale and locally sustainable approaches to meeting needs, rather than large scale planning and technology transfer which over-extends the financial and human resource capacity of councils, or which fails to garner enough political support for change. This also points to the importance of understanding the context in which change takes place, the stakeholders involved, and the limitations of local government. Experience has also supported the importance of strengthening local government through broader democratization and capacity building of communities in 'doing' development. Improving the quality (and quantity) of service delivery through local government can add to the integrity of institutions and the democratic processes which support them. Linking improvements to local government capacity, improved service delivery and democratic accountability with provincial $^{8}$ and national development plans is also likely to be important if gains made are not simply to produce "a pocket of enhanced capacity in unchanged surroundings" (Jones and Blunt 1999, p. 391). In a similar vein, opportunities also need to be taken to broaden the nature of GPS programmes so that local government partnerships act as catalysts of development and increased exchange between communities in Australia and Papua New Guinea.

\section{References}

Askvik, S 1999, 'Twinning in Norwegian development assistance: a response to Jones and Blunt', Public Administration and Development, vol. 19, pp. 403-408.

AusAID 2007, Papua New Guinea-Australia Development Cooperation Strategy 2006-2010, Canberra.

\footnotetext{
${ }^{8}$ For example, AusAID has recently acknowledged the important links between the Provincial Performance Initiative, of which it is a key donor, and the GPS as part of the second phase (2009-2011).
} 
Batterbury, S and Fernando JL 2006, 'Rescaling governance and the impacts of political and environmental decentralisation: An introduction', World Development, vol. 34, no. 11, pp. 1851-1863.

Blair, H 2000, 'Participation and accountability at the periphery: Democratic local governance in six countries', World Development, vol. 28, no. 1, pp. 21-39.

Caulfield, J 2003, 'Local Government Reform in Comparative Perspective', in B Dollery, N Marshall and A Worthington (eds), Reshaping Australian Local Government, University of New South Wales Press, Sydney, pp. 11-34.

CLGF 2007, 'Capacity building through the Good Practice Scheme in PNG', Biannual Progress Report No.1, Commonwealth Local Government Forum Pacific Project.

CLGF Pacific 2008, Commonwealth Local Government Good Practice Scheme: Papua New Guinea, Briefing Note, Commonwealth Local Government Forum.

CLGF 2008, Commonwealth Local Government Good Practice Scheme: Programme Design Document 2009-2011, Commonwealth Local Government Forum.

CLGF 2009, The Good Practice Scheme 2009-2011, accessed 10 March 2009, $<$ http//gps.clgf.org.uk>.

Cooper L 1984, 'The twinning of institutions: its use as a technical assistance delivery mechanism', World Bank Technical Paper 23, World Bank, Washington D.C.

Cremer, RD De Bruin, A and Dupuis A 2001, 'International sister-cities: Bridging the global-local divide', American Journal of Economics and Sociology, vol. 60, no. 1, pp. 377-401.

Devas, N 2001, 'Does city governance matter for the urban poor?', International Planning Studies, vol. 6, no.4, pp.393-408.

Duncan, R 2005, 'An overview of decentralisation and local governance structures in the Pacific region', in Local Democracy and Good Governance in the Pacific: Report of the Regional Symposium held in Suva, Fiji Islands, December 2004, Commonwealth Secretariat, London.

Filer, C 2004, 'Horses for courses: Special purpose authorities and local-level governance in Papua New Guinea', Discussion Paper 2004/6, State, Society and Governance in Melanesia, Australian National University, Canberra.

Government of Papua New Guinea (GoPNG) 2006, Urban governance support project, GoPNG/UNHABITAT.

Green, L Game, C and Delay, S 2005, 'Why should my local authority be involved in an overseas project? Understanding the domestic impacts of local government involvement in international development', University of Birmingham and UK Local Government Alliance for International Development. 
Haley, N 2008, Strengthening civil society to build demand for better governance in the Pacific, State Society and Governance in Melanesia Project Discussion Paper 2008/7, Australian National University, Canberra.

Hasan, A 2006, 'Orangi Pilot Project: the expansion of work beyond Orangi and the mapping of informal settlements and infrastructure', Environment and Urbanization vol. 18, no. 2, pp. 451480

Hassall, G and Tipu, F 2008, 'Local government in the South Pacific islands', Commonwealth Journal of Local Governance, vol. 1, no. 1, May, pp. 6-29.

Hewitt, W E 1999, 'Cities working together to improve urban services in developing areas: The Toronto-Sao Paulo example', Studies in Comparative International Development, vol. 34, no.1, pp. 27-44.

IIED 2004, Reshaping local democracy through participatory governance, Environment and Urbanization Brief 9. London: International Institute for Environment and Development.

Jones, ML and Blunt P 1999, 'Twinning as a method of sustainable institutional capacity building', Public Administration and Development, vol. 19, pp. 381-402.

Klitgaard, R 1997, 'Cleaning up and invigorating the civil service', Public Administration and Development, vol. 17, pp. 487-509.

Kunzmann, K 2005, 'Urban planning in the North: Blueprint for the South?', in M. Keiner et al. (eds) Managing Urban Futures, Ashgate, Aldershot, pp. 235-244.

Lae Urban Local Level Government (LULLG) 2003, Asitiwa Waste management Project (2004-2014) Background Report, Lae Urban Local Level Government/Cairns City Council.

Leeds City Council, 2008, International Relations, Accessed 10 January 2009,

<http://www.leeds.gov.uk/About_Leeds/International_relations.aspx>

May, R 1999, 'Decentralization in Papua New Guinea: Two steps forward, one step back', in M. Turner (ed.) Central-Local Relations in Asia-Pacific, MacMillan, London, pp.123-148.

Mellor, R 2004, The Commonwealth Local Government Good Practice Scheme (Pacific Region) MidTerm Review, UTS Centre for Local Government, Sydney.

National Capital District Commission and Townsville City Council, 2008, Project Hetura, presentation at the Australian/Papua New Guinea Dissemination Workshop, Noosaville $29^{\text {th }}$ May.

Noosa Council, 2008, Report on a visit to Alotau Urban Local Level Government (AULLG), Milne Bay, Papua New Guinea.

Nunan, F and Satterthwaite, D 2001, 'The influence of governance on the provision of environmental infrastructure and services for the low-income groups', International Planning Studies, vol. 6, no. 4 , pp. 409-426. 
Parker, T and Praeger, M 2008, 'Commonwealth Local Government Forum Pacific Project', Commonwealth Journal of Local Governance Issue, vol. 1, no. 1, May, pp. 1-9.

Pluijm, R van der 2007, 'City Diplomacy: The expanding role of cities in international politics', Netherlands Institute of International Relations, The Hague.

Prinsen, G and Titeca, K 2008, 'Uganda's Decentralized Primary Education: Musical Chairs and Inverted Elite Capture in School Management Committees', Public Administration and Development, vol. 28 , no. 2.

Radio Australia 2008 'Garbage piles up in Mt Hagen’, July 7.

Sanyal, B (ed.) 2005 Planning Cultures, Routledge, London.

Schoeffel, P 2003, 'Small is not beautiful: Central government and service delivery in the Pacific', Discussion Paper 2003/7, State, Society and Governance in Melanesia, Australian National University, Canberra.

Spence, R and Ninnes, F 2007, Building relationships across the Timor Sea: An evaluation of the Australian/Timorese friendship agreements', Public Administration and Development, vol. 27, pp. 333-340.

State of Queensland 2007, Report of the Local Government Reform Commission - Volume One, Local Government Reform Commission, Brisbane.

Storey, D 2005, Urban Governance in Pacific Island Countries: Advancing an overdue agenda. State Society and Governance in Melanesia Project Discussion Paper 2005/7, Australian National University, Canberra.

Storey, D Bulloch H and Overton J 2005, 'The Poverty Consensus: Some limitations of the 'popular agenda', Progress in Development Studies, vol. 5, no.1, pp. 30-44.

Sunshine Coast Regional Council and the Alotau Local Level Government 2008a, Partnership between the SCRC and the AULLG, presentation at the Australian/Papua New Guinea Dissemination Workshop, Noosaville $29^{\text {th }}$ May.

Sunshine Coast Regional Council and the Alotau Local Level Government 2008b, CLGF Good Practice Activities Report, May.

Swain, C and Tait, M 2007 'The Crisis of Trust and Planning', Planning Theory and Practice, vol. 8, no. 2, pp. 229-247.

Sykes, S 2002, 'Building capacity for sustainable resource management through Sister City arrangements', http://www.regional.org/au/soc/2002/3/sykes.htm.

Townsville City Council/National Capital District Commission (NCDC), 2008, NCDC/Townsville Hetura II Project, January-June Bi-annual progress report.

Townsville City Council/National Capital District Commission (NCDC), 2007, NCDC/Townsville Hetura II Project, July-December Bi-annual progress report. 
World Bank, 2004, World Development Report 2004: Making Services Work for Poor People, New York, The World Bank Group.

World Bank, 2008, World Development Report 2008: Reshaping Economic Geography, New York, The World Bank Group.

Zelinsky, W 1991, 'The twinning of the world: Sister cities in geographic and historical perspective', Annals of the Association of American Geographers, vol. 8, no. 1, pp. 1-31. 